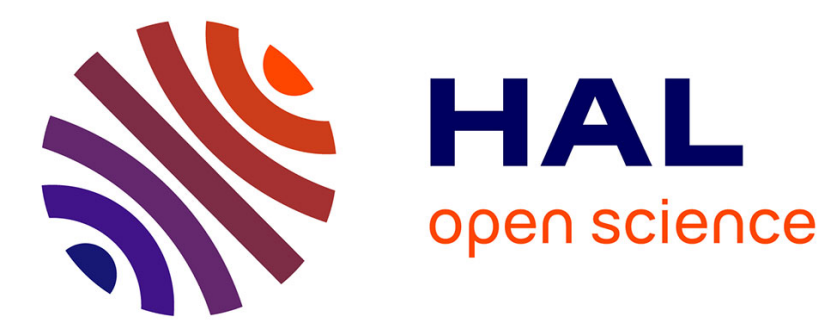

\title{
Eyelid fat grafting: indications, operative technique and complications; a systematic review
}

Elodie Boureaux, Benoit Chaput, Sahar Bannani, Christian Herlin, Antoine

de Runz, Raphael Carloni, Bruno Mortemousque, Frédéric Mouriaux, Eric

Watier, Nicolas Bertheuil

\section{To cite this version:}

Elodie Boureaux, Benoit Chaput, Sahar Bannani, Christian Herlin, Antoine de Runz, et al.. Eyelid fat grafting: indications, operative technique and complications; a systematic review. Journal of Cranio-Maxillofacial Surgery, 2016, 44 (4), pp.374-380. 10.1016/j.jcms.2015.12.013 . hal-01263119

HAL Id: hal-01263119

https://hal-univ-rennes1.archives-ouvertes.fr/hal-01263119

Submitted on 11 Feb 2016

HAL is a multi-disciplinary open access archive for the deposit and dissemination of scientific research documents, whether they are published or not. The documents may come from teaching and research institutions in France or abroad, or from public or private research centers.
L'archive ouverte pluridisciplinaire HAL, est destinée au dépôt et à la diffusion de documents scientifiques de niveau recherche, publiés ou non, émanant des établissements d'enseignement et de recherche français ou étrangers, des laboratoires publics ou privés. 


\section{Eyelid fat grafting: indications, operative technique and complications; a systematic review}

Elodie Boureaux, MD. ${ }^{1,6}$, Benoit Chaput, MD. ${ }^{5}$, Sahar Bannani, MD. ${ }^{1}$, Christian Herlin, MD. ${ }^{7}$, Antoine De Runz, MD. ${ }^{8}$, Raphael Carloni, MD. ${ }^{1}$, Bruno Mortemousque, M.D., PhD. ${ }^{6}$, Frederic Mouriaux, M.D., PhD. ${ }^{6}$ Eric Watier, M.D., PhD. ${ }^{1,2}$, Nicolas Bertheuil, MD., ${ }^{1,2,3,4}$.

1 - Department of Plastic, Reconstructive and Aesthetic Surgery, Hospital Sud, University of Rennes 1, Rennes, France.

2 - INSERM U917, University of Rennes 1, Rennes, France.

3 - SITI Laboratory, Etablissement Français du Sang Bretagne, Rennes University Hospital, Rennes, France.

4 - Stromalab Laboratory, UMR5273 CNRS/UPS/EFS - INSERM U1031, Rangueil Hospital, Toulouse, France.

5 - Department of Plastic, Reconstructive and Aesthetic Surgery, Rangueil Hospital, Toulouse, France.

6 - Department of Ophatmology, Pontchaillou Hospital, University of Rennes 1, Rennes, France.

7 - Department of Plastic and Reconstructive Surgery, Lapeyronie Burn Center, CHU of Montpellier, Montpellier, France.

8 - Department of Plastic and Reconstructive Surgery, CHU of Nancy, Nancy, France. 
Corresponding author:

Dr Nicolas Bertheuil

Department of Plastic, Reconstructive and Aesthetic Surgery, Hospital Sud, Rennes, France.

16 Boulevard de Bulgarie, 35200, Rennes

Phone: 0033299267168

Fax: 0033299266718

E-mail: nbertheuil@gmail.com

Conflict of Interest Disclosures and funding: The authors received no funding support for the research of this article and declared no potential conflicts of interest. 


\section{ABSTRACT}

\section{Introduction}

Many recent studies concerning autologous fat grafting in the eyelids have been published, mostly consisting of case reports and retrospective case series. However, no study on the overall complication or satisfaction rate associated with the various grafting techniques exists. We performed a comprehensive literature review to determine the outcomes and complications of eyelid fat grafting, as well as patient satisfaction.

Methods:

A systematic review of the literature using the PRISMA criteria was conducted. This protocol was registered at the Prospective Register of Systematic Reviews at the National Institute for Health Research.

Results:

Sixteen studies, representing 1,159 patients and published between June 2004 and December 2014, were included. Satisfactory results, judged by clinical examination, were observed in all studies. Few postoperative complications were reported.

\section{Conclusions:}

We demonstrated that the procedures were easy to perform, and achieved satisfactory and sustainable results with few complications in both reconstructive and cosmetic surgery. However, a wide disparity exists in the various fat harvesting, fat purification, and reinjection techniques. Further studies are required to assess the long-term outcomes. Our conclusions should be accepted cautiously due to the small number of articles and the lack of evidence in published studies. 


\section{KEYWORDS}

Eyelid; fat grafting; fat transplantation; lipofilling; adipose-derived stem cell; facial rejuvenation; cosmetic surgery. 


\section{INTRODUCTION}

The loss of facial volume, especially in the periorbital region, is an important component of aging and is due to the redistribution and atrophy of facial fat (Gossain et al., 2005; Le Louarn, 2009; Rohrich et al., 2009; Rohrich \& Pessa, 2007). Traditional approaches to facial rejuvenation have relied on subtractive surgical techniques, focusing on the excision of skin, muscle, and/or fat (Massry \& Azizzadeh, 2005). Modern approaches concentrate instead on filling the "empty” facial compartments, mainly through fat grafting (Serra-Renom \& Sera-Mestre, 2011).

Autologous fat grafting is a technique that has been increasingly used in plastic surgery over the last decade. Initially described by Coleman (Coleman, 1995), fat grafting is used as an adjuvant treatment to blepharoplasty, and can be performed at either the beginning or end of the procedure (Tonnard et al., 2013; Trepsat, 2003). The technique aids facial rejuvenation by increasing the volume in atrophied areas (Trepsat, 2003). Furthermore, it allows for the regeneration of treated areas due to the presence of adipose-derived stem cells (ASCs) via the synthesis of trophic and immunomodulatory factors (Bertheuil et al., 2015). Because of this, fat grafting has practical applications in both reconstructive and cosmetic surgery.

The objective of this review was to define the indications for eyelid fat grafting, outline the available techniques, assess the results, operative morbidity, and patient satisfaction, and clarify its role in popularizing facial rejuvenation. 


\section{MATERIALS AND METHODS}

Study design

We conducted a systematic literature review to assess the level of interest in the eyelid fat grafting procedure, outline the available techniques, and assess complications and patient satisfaction.

This review was undertaken in accordance with the PRISMA (Preferred Reporting Items for Systematic Reviews and Meta-analysis) criteria. This protocol, which follows the AMSTAR (A Measurement Tool to Assess Systematic Reviews) criteria, was registered at the Prospective Register of Systematic Reviews at the National Institute of Health Research (NIHR), and is available online:

(http://www.crd.york.ac.uk/PROSPERO/display_record.asp?ID=CRD42015015759).

We interrogated the MEDLINE database via PubMed and the Cochrane Library in December 2014 using the following keywords: ["fat grafting" OR "fat transplantation" OR "fat injection" OR "lipofilling" OR "lipotransfer" OR "lipomodeling" OR "adipose derived stem cell" AND "eyelid" OR "periocular"]. The references of collected articles were also examined to identify relevant articles.

The titles, abstracts, and full text of the retrieved articles were examined by two reviewers (EB and NB), and disagreements were resolved by consensus. Where it was not possible to reach consensus, one of the senior authors was required to make the final decision (BC). 


\section{Selection criteria}

Original articles published between June 2004 and December 2014, related to patients who had received eyelid(s) fat grafting, were included in this review. These articles included prospective controlled clinical trials, prospective or retrospective observational studies, and clinical cases. Excluded articles included those written in languages other than English or French, those that involved animal testing, letters to editors, duplicates, and those reporting data from other studies without including original data of their own.

\section{Data collection}

Two independent reviewers undertook a detailed and critical reading of each complete article to obtain the following data: authors, publication date, place of study, article type and evidence level, number of patients, indications, surgical technique, complications, and the therapeutic possibilities suggested by the authors. The data were organized into a table using Microsoft Excel ${ }^{\circledR} 2011$ (Microsoft Corp., Redmond, WA, USA). For each article, a level of evidence, as defined by the Oxford Centre for Evidence-Based Medicine (EBM), was awarded (Table 1).

\section{RESULTS}

Among the 218 articles initially identified by our search, 16 were finally selected (Fig. 1) and these included 1,159 patients (Fig. 2). Most of the articles were published after 2010 
(Fig. 3), had a low level of evidence (Table 1), and were principally North American, European, and Asian publications (Tables 1 and 2).

\section{Indications}

Eyelid fat grafting had indications in aesthetic and reconstructive surgery. Aesthetically, the main surgical indications were the correction of dark circles (Roh et al., 2009), as an adjuvant to blepharoplasty, or as an alternative treatment for hollow eyes and malar bags (Tonnard et al., 2013). Photographs of patients at a younger age were occasionally needed to better assess age-related volume loss (Tonnard et al., 2013; Ciuci \& Obagi, 2008).

In reconstructive surgery, fat grafting could be employed after eyelid trauma, posttreatment for eyelid tumors (post-surgery or post-radiotherapy), in congenital malformations, dysmorphic syndromes affecting the eyelids (Parry-Romberg syndrome (Clauser et al., 2010; Clauser et al., 2011), Treacher Collins syndrome (Clauser et al., 2011)), burns, scars, eyelid sequelae of facial paralysis, scleroderma, and sequelae of chronic radiodermatitis (Clauser et al., 2011). A case of ectropion secondary to a burn scar treated by fat grafting was also described with good results in terms of ocular symptoms (Caviggioli et al., 2008).

\section{Preoperative preparation}

None of the authors recommended a particular preoperative ophthalmologic assessment 
or any complementary tests. The procedure was performed under either general anesthesia (Tonnard et al., 2013; Clauser et al., 2010; Clauser et al., 2011; Lee et al., 2011; Duhoux et al., 2013; Lin et al., 2014) or local anesthesia (Serra-Renom \& SerraMestre, 2011; Clauser et al., 2011; Caviggioli et al., 2008; Lin et al., 2014; Le et al., 2014) with lidocaine $2 \%$ and diluted adrenaline $1 / 200,000$ (Serra-Renom \& Serra-Mestre, 2011) to $1 / 1,000,000$ (Tonnard et al., 2013). Tonnard was of the opinion that another type of eyelid surgery (e.g., blepharoplasty) could be performed simultaneously (Tonnard et al., 2013).

\section{Fat-harvesting}

Fat was harvested from the abdomen (Serra-Renom \& Serra-Mestre, 2011; Tonnard et al., 2013; Roh et al., 2009; Clauser et al., 2010; Clauser et al., 2011; Caviggioli et al., 2008; Lee et al., 2011; Duhoux et al., 2013; Lin et al., 2014; Thaunat et al., 2004; Tonnard et al., 2013; Einan-Lifshitz et al., 2013), hips (Tonnard et al., 2013), trochanteric regions (Clauser et al., 2011), thighs (Tonnard et al., 2013; Clauser et al., 2011; Le et al., 2014; Einan-Lifshitz et al., 2013), and/or medial aspect of the knees (Clauser et al., 2011; Le et al., 2014), with a preference for the infra-umbilical fat (Serra-Renom \& Serra-Mestre, 2011; Clauser et al., 2010; Caviggioli et al., 2008; Lee et al., 2011; Duhoux et al., 2013; Lin et al., 2014; Thaunat et al., 2004; Tonnard et al., 2013). Roh et al. also harvested fat from the buttocks (Roh et al., 2009). The choice of donor site did not appear to affect the end result.

The technique employed by Coleman (Lin et al., 2014) was used by most authors to 
harvest fat. Fat was removed by applying a manual negative pressure, with the aid of a 3mm blunt tip cannula (Serra-Renom \& Serra-Mestre, 2011; Tonnard et al., 2013; Clauser et al., 2011; Tonnard et al., 2013) - 14-gauge (Roh et al., 2009; Le et al., 2014) or 18gauge (Youn et al., 2013) - attached to a 10-cc LuerLock® syringe (Serra-Renom \& Serra-Mestre, 2011; Tonnard et al., 2013; Roh et al., 2009; Clauser et al., 2011; Lin et al., 2014; Tonnard et al., 2013; Einan-Lifshitz et al., 2013; Youn et al., 2013) with 1 mm holes (Tonnard et al., 2013). Harvesting needed to be symmetrical, regular, and sufficiently deep under the superficial fascia to leave no sequelae at the donor site. Some authors stated that they applied a gentle negative pressure with the plunger pulled no more than $2 \mathrm{~mL}$ at a time to prevent an impact from excessive negative pressure on the survival of adipocytes (Clauser et al., 2011; Einan-Lifshitz et al., 2013; Youn et al., 2013).

Treatment of fat (fat-processing/purification)

Most authors used centrifugation (Serra-Renom \& Serra-Mestre, 2011; Clauser et al., 2010; Clauser et al., 2011; Caviggioli et al, 2008; Duhoux et al., 2013; Lin et al., 2014; Thaunat et al., 2004) at 3,000 rpm for 3 minutes (Serra-Renom \& Serra-Mestre, 2011; Clauser et al., 2010; Clauser et al., 2011; Caviggioli et al., 2008; Lin et al., 2014) to process the fat, after which three levels were observed in the syringe. The lower level corresponded to hematopoietic and endothelial cells as well as local anesthetics. The upper level was oily and contained the adipocytes destroyed during collection and centrifugation (Serra-Renom \& Serra-Mestre, 2011; Clauser et al., 2011). This level was 
eliminated because it can decrease the grafted fat take and cause oil cysts to form. Only the intermediate level was used for reinjection. In addition, some authors preferred to use a nylon filter (Tonnard et al., 2013; Tonnard et al., 2013), a sheet of paper (Roh et al., 2009), a Telfa dressing pad (Einan-Lifshitz et al., 2013), or even a steel sieve (Le et al., 2014) to filter the fat, without any sufficient level of evidence demonstrating the superiority of a particular purification technique.

\section{Reinjection of fat}

Fat reinjection was an important step in the overall success of the graft. The fat lobules needed to be distributed in the least traumatic way possible, within a nurturing environment, to survive. The reinjection site could be infiltrated with lidocaine $0.3 \%$ and/or diluted adrenaline at 1/600,000 in the case of general anesthesia, and with lidocaine $1 \%$ and epinephrine $1 / 200,000$ in the case of local anesthesia (Tonnard et al., 2013).

The reinjection of the fat was performed with a 17-gauge (Serra-Renom \& Serra-Mestre, 2011), 18-gauge (Roh et al., 2009; Caviggioli et al., 2008; Lin et al., 2014), 16 to 19gauge (Le et al., 2014), 19-gauge (Einan-Lifshitz et al., 2013), 19 to 21-gauge (Tonnard et al., 2013), or even a 22-gauge (Youn et al., 2013) cannula in the case of treatment by "collagenase fat-grafting", while a 27-gauge cannula was used for "nanofat-grafting" (Tonnard et al., 2013). The cannula was connected to a 10-mL (Duhoux et al., 2013) or 1mL LuerLock® syringe (Serra-Renom \& Serra-Mestre, 2011; Tonnard et al, 2013; Roh et al., 2009; Clauser et al., 2011; Lin et al., 2014; Le et al., 2014; Einan-Lifshitz et al., 2013; 
Youn et al., 2013). Traditional fat-grafting techniques have evolved toward microfilling with the use of increasingly small cannulas.

Fat was injected in longitudinal tunnels that formed a three dimensional (3D) mesh to promote revascularization and graft survival, per Coleman's technique (Serra-Renom \& Serra-Mestre, 2011).

In the upper eyelids, fat grafting was generally used to fill hollow eyelids. The injections were sometimes carried out in conjunction with blepharoplasty (Lin et al., 2014). The injection sites were located at the medial $2 / 3$ of the upper eyelid, the infero-medial $1 / 3$ of the eyebrow, and the lateral part of the eyebrow (Tonnard et al., 2013). The injected volume ranged between $0.5-2.5 \mathrm{cc}$, as judged necessary to fill the volume loss (Tonnard et al., 2013). Some authors advocated blepharoplasty after fat grafting due to anatomical changes induced by the latter (Trepsat, 2003).

In the lower eyelids, fat grafting helped to restore volume, including that of the periorbital region. The injection points were located external to the zygomatic bone (Tonnard et al., 2013; Le et al., 2014) and at “the valley of tears” (Le et al., 2014). Injections were avoided in-between the skin and muscle in this area, due to the thinness of the skin, which may lead to palpable irregularities (Serra-Renom \& Serra-Mestre, 2011). The injected quantities ranged from 0.5 to 10 сc (Tonnard et al., 2013; Roh et al., 2009; Caviggioli et al., 2008; Le and al., 2014) according to the degree of volume loss (Tonnard et al., 2013). Some authors performed fat grafting after blepharoplasty (EinanLifshitz et al., 2013). Bilateral injections using fat collected from one area were suggested to avoid postoperative asymmetry, since the fat quality may vary according to the 
collection site (Duhoux et al., 2013).

\section{Patient Satisfaction}

Only four studies (25\%) assessed the patients' satisfaction, and all of them reported a high rate of between 78\% and 100\% (Serra-Renom \& Serra-Mestre, 2011; Roh et al., 2009; Lin et al., 2014; Youn et al., 2013).

Lin et al. noted that 167 of 168 patients were satisfied, with no explanation of the method of evaluation (Lin et al., 2014). Serra-Renom employed two non-validated scales at 24 months, one completed by the patients and the other by an independent medical team, using an ascending scale ranging from 1 to 4 (poor, fair, good, and excellent) (SerraRenom \& Serra-Mestre, 2011). The mean score awarded by the patients was 3.91 (93.79\% of patients reported excellent results) versus 3.97 awarded by the medical team (97.67\% excellent results). Roh et al. (2009) evaluated their results using a similar questionnaire by an independent medical team at 3 months post-operation. The average score of their 10 patients was 2.6. Youn et al. (2013) evaluated their results for correction of dark circles using the Fitzpatrick scale, a recognized tool for dermatological research into skin pigmentation (grades 1-6). Patients were divided into three groups (worse, no change, improved), and the final results indicated that $67.1 \%$ of the patients had improved, 28\% remained unchanged, and 4.9\% were worse.

\section{Complications}


The majority of the reported complications were minor (Tonnard et al., 2013; EinanLifshitz et al, 2013). The main “complication” was the resorption of fat (Lin et al., 2014; Einan-Lifshitz et al., 2013), evidenced by clinical examination (Trepsat et al., 2003; Clauser et al., 2011), for which the authors used supplementary injections of fat or synthetic products (Einan-Lifshitz et al., 2013). None of the studies used any tests to determine the rate of resorption.

Other complications included bruising and swelling persisting beyond 15 days (Lin et al., 2014), which could be reduced by applying ice, asymmetry (Serra-Renom \& SerraMestre, 2011), migration of fat (Serra-Renom \& Serra-Mestre, 2011), calcifications, and paresthesia. Fat hypertrophy was identified by Tonnard et al. (2013), in one patient out of 500, and by Duhoux et al. (2013), and occurred after postoperative weight changes. Correction of fat hypertrophy could take place by liposuction under local anesthesia (Tonnard et al., 2013) or by direct excision (Duhoux et al., 2013). Lipogranuloma (Le et al., 2014) could be treated by surgical excision, or by a local or systemic steroid injection (Le et al., 2014; Sa et al., 2011). Granulomas could be found in periorbital areas, away from the injection site, e.g., after a forehead fat injection (Sa et al., 2011).

Over-corrections and irregularities (Roh et al., 2009) could be treated with massage, excision, liposuction, and/or corticosteroid injections in the grafted fat to allow it to atrophy (Le et al., 2014; Sa et al., 2011).

More serious complications, such as central retinal artery occlusion (Lee et al., 2011; Chen et al., 2014) and multiple cerebral infarctions (Lee et al., 2011; Thaunat et al., 2004) - sometimes concomitantly (Lee et al., 2011) - were reported, mainly in the case of 
injection into the glabella and forehead, and rarely during the treatment of the upper eyelids (Lee et al., 2011; Chen et al., 2014). These occlusions left major sequelae, particularly when the occlusion was complete (Chen et al., 2014; Park et al., 2012). A patient who had received an eye massage, treatment by intravenous mannitol, and oxygen therapy experienced no visual improvement (Lee et al., 2011). These complications appeared to be secondary to fat embolism (Thaunat et al., 2004). A case of severe diplopia was described after fat hypertrophy in a patient who gained $15 \mathrm{~kg}$ within 2 years of fat grafting. Magnetic resonance imaging (MRI) identified a mass of subcutaneous fat reaching the orbital floor through an inferior septal defect. After excision of the mass, the symptoms disappeared completely (Duhoux et al., 2013).

New perspectives - mesenchymal stem cell therapy from adipose tissue

The use of fat grafting has undergone exponential growth since its popularization by Coleman. While initially used to reverse volume loss caused by different etiologies, this technique has also expanded into regenerative and reparative medicine due to the discovery of mesenchymal stem cells (MSCs) within the adipose tissue (Zuk et al., 2001), termed adipose-derived stem cells (ASCs). These cells are particularly advantageous for tissue regeneration; they act by supporting neoangiogenesis as well as through the reduction of inflammation and tissue fibrosis (Bertheuil et al., 2015). This explains the rapid development in regenerative medicine in recent years due to the invention of techniques - in contrast to fat grafting - that rely on the transfer of the stromal vascular fraction containing these cells (Tonnard et al., 2013; Youn et al., 2013). Injection of 
stromal cells into tissue already treated by standard fat grafting techniques has led to improvements in graft survival, mainly by enhancing angiogenesis (Kolle et al., 2013).

Two of the studies in our review used this concept. The first study reported treatment of 91 patients for dark circles with the enzymatic digestion of adipose tissue that had been centrifuged using Coleman’s technique. The intermediate level was digested by collagenase type 2 derived from Clostridium histolyticum (Sigma-Aldrich, St. Louis, USA) for 25 minutes at $37^{\circ} \mathrm{C}$, after which the product was washed, centrifuged, and then injected into the patients. The authors reported a clinical improvement at 3 months by comparing pre- and postoperative photographs taken by three different doctors and rating the results as either improved, unchanged, or worse. According to this classification system, $67.1 \%$ of patients had improved, $28 \%$ remained unchanged, and $4.9 \%$ were found to be worse. In this study, the reinjected product corresponded to the stromal vascular fraction. However, no real characterization of the product was undertaken.

The second study (Tonnard et al., 2013) concerned 67 patients who were treated for superficial rhytides, scars, and dark circles by "nanofat grafting”. The fat was mechanically treated by passing it 30 times from one 10-cc syringe into another, allowing fragmentation and the formation of an emulsion. The authors attempted to characterize the product by demonstrating the absence of surviving adipocytes and the probable presence of MSCs. However, they did not provide sufficient evidence to indicate that these were actually ASCs. No adverse effects were observed, and the quality of the treated skin at 6 months post-operation was found to be significantly improved, which was very promising. 


\section{DISCUSSION}

The transfer of adipose tissue was described for the first time in the late 19th century. A century later, following its popularization by Coleman, this technique has gained a prominent place within plastic, reconstructive, and aesthetic surgery. The objectives of fat grafting have since doubled; the primary goal was the reversal of a loss of substance; however, in the last decade it has been increasingly used for tissue regeneration. These use of these techniques is increasing exponentially in regenerative surgery due to the presence of MSCs that, through the synthesis of trophic and immunomodulatory factors, promote neoangiogenesis and decrease inflammation and local tissue fibrosis. A greater understanding of facial aging mechanisms - consisting of fat atrophy and ptosis of the different facial compartments - has allowed fat grafting to be considered as a possible technique for facial rejuvenation, particularly of the eyelids.

Our literature review included more than 1,159 patients worldwide, and thus provides an overview of current international practice. It is interesting to note that, at present, the literature includes only retrospective studies and clinical cases, and therefore the level of evidence regarding this subject is still weak (3 to 5 EBM). The main indication for eyelid-lipofilling was aesthetic concerns (1,096 patients) such as dark circles (159 patients, $14.5 \%$ of aesthetic surgery). Another major indication was reconstruction by filling-in substance loss regardless of the cause.

Currently, there is no evidence in the literature to support a specific standardization of the procedure (Gir et al., 2012). The main innovations included the development of 
associated technologies to improve graft survival, such as stem cell enrichment. These methods are encouraging (Arononowitz \& Ellenhorn, 2013); however, their broad application is difficult given the cost and ethical constraints (Kolle et al., 2013).

The cosmetic results of the procedure appeared to be satisfactory according to most of the authors. Nevertheless, an objective assessment tool of the end result was lacking . Contrary to breast fat grafting, no study had evaluated the rate of resorption of the grafted fat in the eyelids. This type of research - whether by MRI (Gosain et al., 2005) or by other methods (Guibert et al., 2013) - is required to analyze the retention rate and overall rejuvenation of the eyelids.

This paper demonstrates that postoperative complications arising from the fat grafting procedure were few and were usually minor. The major complication we identified was cerebral or ocular artery thrombosis, but that was exceptional and mainly occurred in the case of injections in dangerous areas such as the glabella and nasolabial folds (Park et al., 2008). It was almost always linked to an increase in local pressure resulting in a reflux of the fat into the ophthalmic artery and the internal carotid artery (Park et al., 2008). To limit this risk (which can be made worse by vascular injury), and the risks of fat embolism and serious consequences, verification of an absence of blood reflux into the syringe prior to injection, slow injection at low pressure, and the use of a blunt-tip cannula, were recommended (Park et al., 2008).

Fat hypertrophy was reported $(n=2 / 1,159)$ after significant weight gain following the intervention. Patients should therefore be warned before the operation that a stable postoperative weight is required. 
The current area of research interest concerns the development of microfat grafting techniques in addition to injection of the stromal vascular fraction (SVF) into adipose tissue, which is of particular interest for facial rejuvenation treatments including those for dark circles. Several techniques are being developed to extract fractions containing ASC, their methods being either enzymatic (Youn et al., 2013) or mechanical (Tonnard et al., 2013; Raposio et al., 2014). Indeed, these authors demonstrated the possibility of an SVF graft without the digestion of the tissues by proteolytic enzymes and, more importantly, without expensive specialized devices (Aronowitz \& Ellenhorn, 2013). However, none of these studies characterized the product they reinjected for assessment of the presence of viable ASCs and their proportions. In addition, none had demonstrated the stemness (Dominici et al., 2006) of the injected SVF cells. These cells were defined in vitro by several criteria (Bertheuil \& Chaput, 2015).

This study had several limitations. First, there was a language bias because our inclusion criteria only allowed for selection of articles in English or French. Second, despite the fact that the fat grafting procedure is now fully developed, our study showed that the level of evidence within published series remains insufficient. None of the articles included in our study adequately measured their results; for example, there was a lack of evaluation of the fat retention rates, long-term outcome of the patients, or satisfaction rate; there was also no assessment of quality of life after surgery using validated instruments. Therefore, we were unable to reach firm conclusions regarding all of these points. It is essential to continue the ongoing work to fully characterize the products reinjected into patients, so that their mechanisms of action can be clarified and also to ensure fewer random results. 
Further studies are required to optimize the collection, processing, and reinjection of fat, especially with respect to those techniques that are not strictly concerned with fat grafting but rather with SVF grafting. These techniques - whether they are associated with traditional fat grafting or not - provide encouraging results and suggest that graft survival could be improved. Furthermore, patients in some studies appeared to have a lower associated morbidity than for conventional fat grafting.

\section{CONCLUSION}

Most facial volume loss is due to fat atrophy, for which autologous fat grafting is the ideal form of tissue replacement. Fat grafting is therefore a possible technique for reshaping the eyelids and correcting their flaws.

This literature review revealed that fat grafting procedures were easy to perform, and achieved satisfactory and sustainable results with few complications in both reconstructive and cosmetic surgery.

Eyelid fat grafting appears to be a promising tool, but we have highlighted the existence of a wide disparity in the fat harvesting, fat purification, and reinjection techniques. Moreover, further studies are required to assess long term outcomes, such as the fat retention rate, which have not been addressed in the studies included in this review. Likewise, new modalities such as stromal vascular fraction grafting are in development, and these will open new doors in regenerative and reconstructive surgery.

However, our work has shown that any conclusions must be made cautiously due to the 
small number of articles available and the lack of evidence in the published studies.

The English in this document has been checked by at least two professional editors, both native speakers of English. For a certificate, please see:

http://www.textcheck.com/certificate/5zevvS 


\section{REFERENCES}

Aronowitz JA, Ellenhorn JD. Adipose stromal vascular fraction isolation: a head-to-head comparison of four commercial cell separation systems. Plast Reconstr Surg 132:932e-9e, 2013.

Bertheuil N, Chaput B, Menard C, et al. [Adipose-derived stromal cells: History, isolation, immunomodulatory properties and clinical perspectives]. Ann Chir Plast Esthet 60:94-102, 2015.

Bertheuil N, Chaput B. A novel and effective strategy for the isolation of adipose-derived stem cells: minimally manipulated adipose-derived stem cells for more rapid and safe stem cell therapy. Plast Reconstr Surg 135:454e-5e, 2015.

Caviggioli F, Klinger F, Villani F, Fossati C, Vinci V, Klinger M. Correction of cicatricial ectropion by autologous fat graft. Aesthetic Plast Surg 32:555-7, 2008.

Chen Y, Wang W, Li J, Yu Y, Li L, Lu N. Fundus artery occlusion caused by cosmetic facial injections. Chin Med J 127:1434-7, 2014.

Ciuci PM, Obagi S. Rejuvenation of the periorbital complex with autologous fat transfer: current therapy. J Oral Maxillofac Surg 66:1686-93, 2008.

Clauser LC, Tieghi R, Consorti G. Parry-Romberg syndrome: volumetric regeneration by structural fat grafting technique. J Craniomaxillofac Surg 38:605-9, 2010.

Clauser LC, Tieghi R, Galie M, Carinci F. Structural fat grafting: facial volumetric restoration in complex reconstructive surgery. J Craniofac Surg 22:1695-701, 2011.

Coleman SR. Long-term survival of fat transplants: controlled demonstrations. Aesthetic Plast Surg 19:421-5, 1995. 
Dominici M, Le Blanc K, Mueller I, et al. Minimal criteria for defining multipotent mesenchymal stromal cells. The International Society for Cellular Therapy position statement. Cytotherapy 8:315-7, 2006.

Duhoux A, Chennoufi M, Lantieri L, Hivelin M. Complications of fat grafts growth after weight gain: report of a severe diplopia. J Plast Reconstr Aesthet Surg 66:987-90, 2013.

Einan-Lifshitz A, Holds JB, Wulc AE, Hartstein ME. Volumetric rejuvenation of the tear trough with repo and Ristow. Ophthal Plast Reconstr Surg 29:481-5, 2013.

Gir P, Brown SA, Oni G, Kashefi N, Mojallal A, Rohrich RJ. Fat grafting: evidence-based review on autologous fat harvesting, processing, reinjection, and storage. Plast Reconstr Surg 130:249-58, 2012.

Gosain AK, Klein MH, Sudhakar PV, Prost RW. A volumetric analysis of soft-tissue changes in the aging midface using high-resolution MRI: implications for facial rejuvenation. Plast Reconstr Surg 115:1143-52, 2005.

Guibert M, Franchi G, Ansari E, et al. Fat graft transfer in children's facial malformations: a prospective three-dimensional evaluation. J Plast Reconstr Aesthet Surg 66:799-804, 2013.

Kolle SF, Fischer-Nielsen A, Mathiasen AB, et al. Enrichment of autologous fat grafts with ex-vivo expanded adipose tissue-derived stem cells for graft survival: a randomised placebocontrolled trial. Lancet 382:1113-20, 2013.

Le TP, Peckinpaugh J, Naficy S, Amadi AJ. Effect of autologous fat injection on lower eyelid position. Ophthal Plast Reconstr Surg 30:504-7, 2014.

Le Louarn C. [Midface region: functional anatomy, ageing process, indications and concentric malar lift]. Ann Chir Plast Esthet 54:411-20, 2009.

Lee CM, Hong IH, Park SP. Ophthalmic artery obstruction and cerebral infarction following periocular injection of autologous fat. Korean J Ophthalmol 25:358-61, 2011. 
Lin TM, Lin TY, Chou CK, Lai CS, Lin SD. Application of microautologous fat transplantation in the correction of sunken upper eyelid. Plast Reconstr Surg Glob Open 2(11):e259, 2014.

Massry GG, Azizzadeh B. Periorbital fat grafting. Facial Plast Surg 29:46-57, 2005.

Park SH, Sun HJ, Choi KS. Sudden unilateral visual loss after autologous fat injection into the nasolabial fold. Clin Ophthalmol 2:679-83, 2008.

Park SW, Woo SJ, Park KH, Huh JW, Jung C, Kwon OK. Iatrogenic retinal artery occlusion caused by cosmetic facial filler injections. Am J Ophthalmol 154:653-62, 2012.

Raposio E, Caruana G, Bonomini S, Libondi G. A novel and effective strategy for the isolation of adipose-derived stem cells: minimally manipulated adipose-derived stem cells for more rapid and safe stem cell therapy. Plast Reconstr Surg 133:1406-9, 2014.

Roh MR, Kim TK, Chung KY. Treatment of infraorbital dark circles by autologous fat transplantation: a pilot study. Br J Dermatol 160:1022-5, 2009.

Rohrich RJ, Pessa JE. The fat compartments of the face: anatomy and clinical implications for cosmetic surgery. Plast Reconstr Surg 119:2219-27, 2007.

Rohrich RJ, Arbique GM, Wong C, Brown S, Pessa JE. The anatomy of suborbicularis fat: implications for periorbital rejuvenation. Plast Reconstr Surg 124:946-51, 2009.

Sa HS, Woo KI, Suh YL, Kim YD. Periorbital lipogranuloma: a previously unknown complication of autologous fat injections for facial augmentation. Br J Ophthalmol 95:125963, 2011.

Serra-Renom JM, Serra-Mestre JM. Periorbital rejuvenation to improve the negative vector with blepharoplasty and fat grafting in the malar area. Ophthal Plast Reconstr Surg 27:442-6, 2011.

Thaunat O, Thaler F, Loirat P, Decroix JP, Boulin A. Cerebral fat embolism induced by facial fat injection: Plast Reconstr Surg. 113(7):2235-6, 2004. 
Tonnard P, Verpaele A, Peeters G, Hamdi M, Cornelissen M, Declercq H. Nanofat grafting: basic research and clinical applications. Plast Reconstr Surg 132:1017-26, 2013.

Tonnard PL, Verpaele AM, Zeltzer AA. Augmentation blepharoplasty: a review of 500 consecutive patients. Aesthet Surg J 33:341-52, 2013.

Trepsat F. Periorbital rejuvenation combining fat grafting and blepharoplasties. Aesthetic Plast Surg 27:243-53, 2003.

Youn S, Shin JI, Kim JD, Kim JT, Kim YH. Correction of infraorbital dark circles using collagenase-digested fat cell grafts. Dermatol Surg 39:766-72, 2013.

Zuk PA, Zhu M, Mizuno H, et al. Multilineage cells from human adipose tissue: implications for cell-based therapies. Tissue Eng 7:211-28, 2001. 
Table 1 - Presentation of publications, country and level of Evidence Based Medicine.

\begin{tabular}{lccc}
\hline Article & Country & Study design & Evidence level \\
\hline & & & 5 \\
Thaunat O, 2004 & France & Case report & 3 \\
Caviggioli F, 2008 & Italy & Retrospective cohort & 3 \\
Roh MR, 2009 & South Korea & Retrospective cohort & 5 \\
Clauser LC, 2010 & Italy & Case report & 5 \\
Lee C, 2011 & South Korea & Case report & 4 \\
Sa HS, 2011 & South Korea & Case series & 3 \\
Clauser LC, 2011 & Italy & Retrospective cohort & 3 \\
Serra Renom J, 2011 & Spain & Retrospective cohort & 5 \\
Duhoux A, 2013 & France & Case report & 3 \\
Youn S, 2013 & South Korea & Retrospective cohort & 3 \\
Tonnard P, 2013 & Belgium & Retrospective cohort & 3 \\
Tonnard P, 2013 & Belgium & Retrospective cohort & 3 \\
Einan Lifshitz A, 2013 & USA & Retrospective cohort & 4 \\
Chen Y, 2014 & China & Case series & 3 \\
Lin TM, 2014 & China & Retrospective cohort & 3 \\
Le TP, 2014 & USA & Retrospective cohort & \\
& & & \\
\hline
\end{tabular}


Table 2 - Geographical distribution of publications and patients.

\begin{tabular}{ccc}
\hline Country of origin & Number of articles & Number of patients \\
\hline South Korea & 4 & 102 \\
Italy & 3 & 49 \\
Belgium & 2 & 567 \\
China & 2 & 175 \\
France & 2 & 2 \\
USA & 2 & 127 \\
Spain & 1 & 142 \\
& & \\
\hline
\end{tabular}




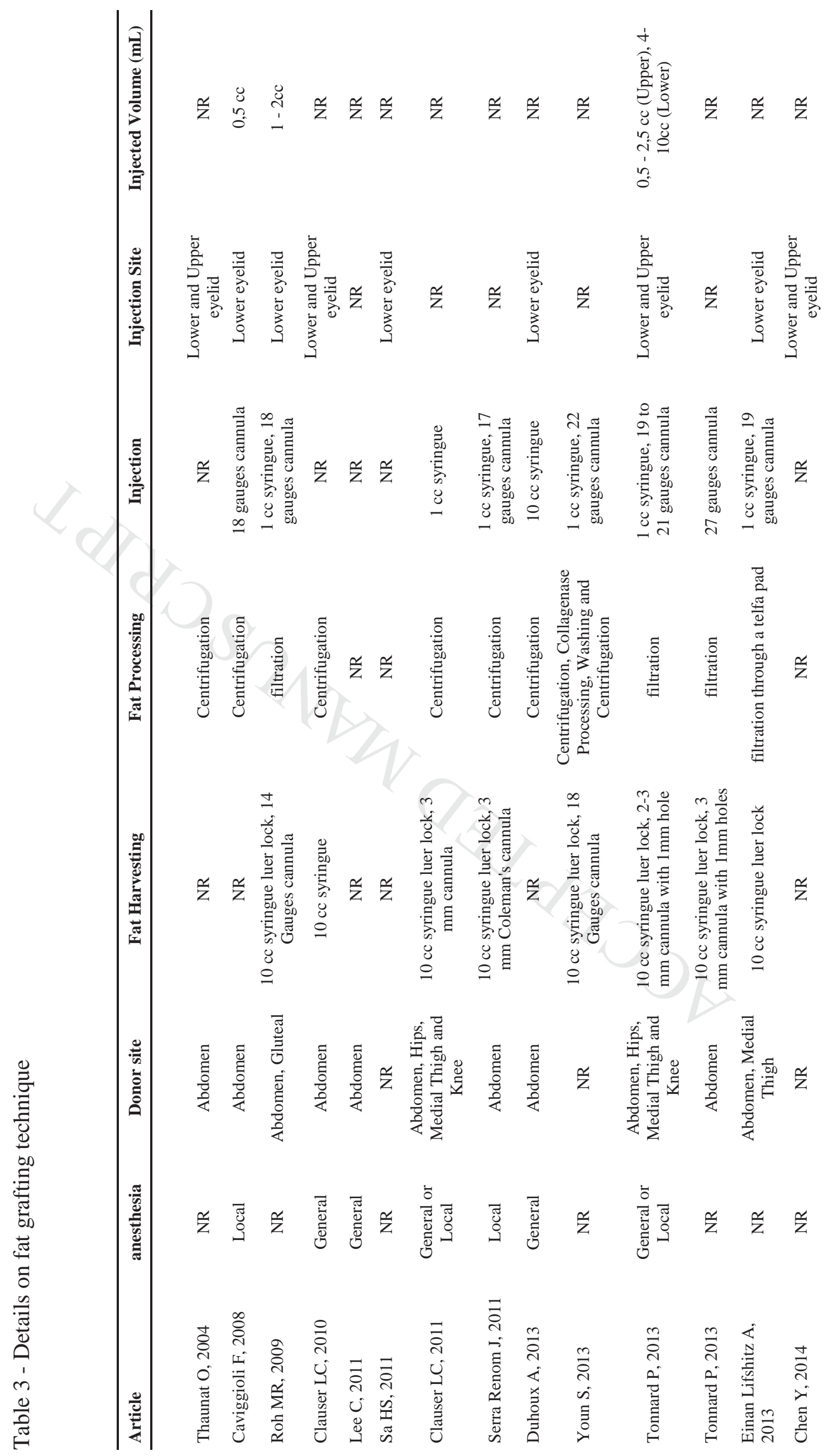




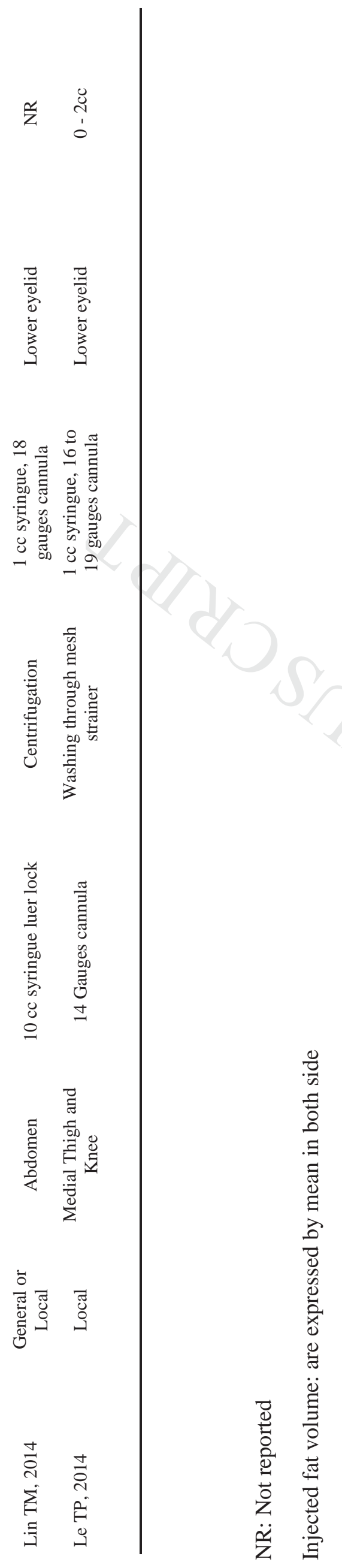


Table 4 - Indications and complications

\begin{tabular}{|c|c|c|c|}
\hline Article & $\begin{array}{l}\text { Number of } \\
\text { patients }\end{array}$ & Indications & complications \\
\hline Thaunat O, 2004 & 1 & Reconstruction & cerebral infarction \\
\hline Caviggioli F, 2008 & 1 & Reconstruction & NR \\
\hline Roh MR, 2009 & 10 & Aesthetic (dark eyelid) & No \\
\hline Clauser LC, 2010 & 1 & Reconstruction & \\
\hline Lee C, 2011 & & & $\begin{array}{l}\text { ophthalmic artery } \\
\text { occlusion, cerebral }\end{array}$ \\
\hline & 1 & NR & infarction \\
\hline Sa HS, 2011 & 9 & NR & Granuloma $(n=1)$ \\
\hline Clauser LC, 2011 & 47 & Reconstruction & No \\
\hline Serra Renom J, 2011 & 142 & Aesthetic & fat asymmetry $(\mathrm{n}=1)$ \\
\hline Duhoux A, 2013 & 1 & Reconstruction & fat growth, diplopia \\
\hline Youn S, 2013 & 82 & Aesthetic (dark eyelid) & No \\
\hline Tonnard P, 2013 & 500 & Aesthetic & $\begin{array}{l}\text { fat growth }(n=1) \text {, scleral } \\
\text { show }(n=5)\end{array}$ \\
\hline Tonnard P, 2013 & 67 & $\begin{array}{l}\text { Aesthetic (skin } \\
\text { rejuvenation) }\end{array}$ & No \\
\hline $\begin{array}{l}\text { Einan Lifshitz A, } \\
2013\end{array}$ & 57 & Aesthetic & $\begin{array}{l}\text { under correction with } \\
\text { reoperation }(n=2)\end{array}$ \\
\hline Chen Y, 2014 & 2 & & $\begin{array}{l}\text { ophthalmic artery occlusion } \\
(\mathrm{n}=2)\end{array}$ \\
\hline Lin TM, 2014 & 168 & Aesthetic (sunken eyelid) & $\begin{array}{l}\text { under correction with } \\
\text { reoperation }(n=1)\end{array}$ \\
\hline Le TP, 2014 & 70 & Aesthetic & No \\
\hline
\end{tabular}

NR: Not reported 


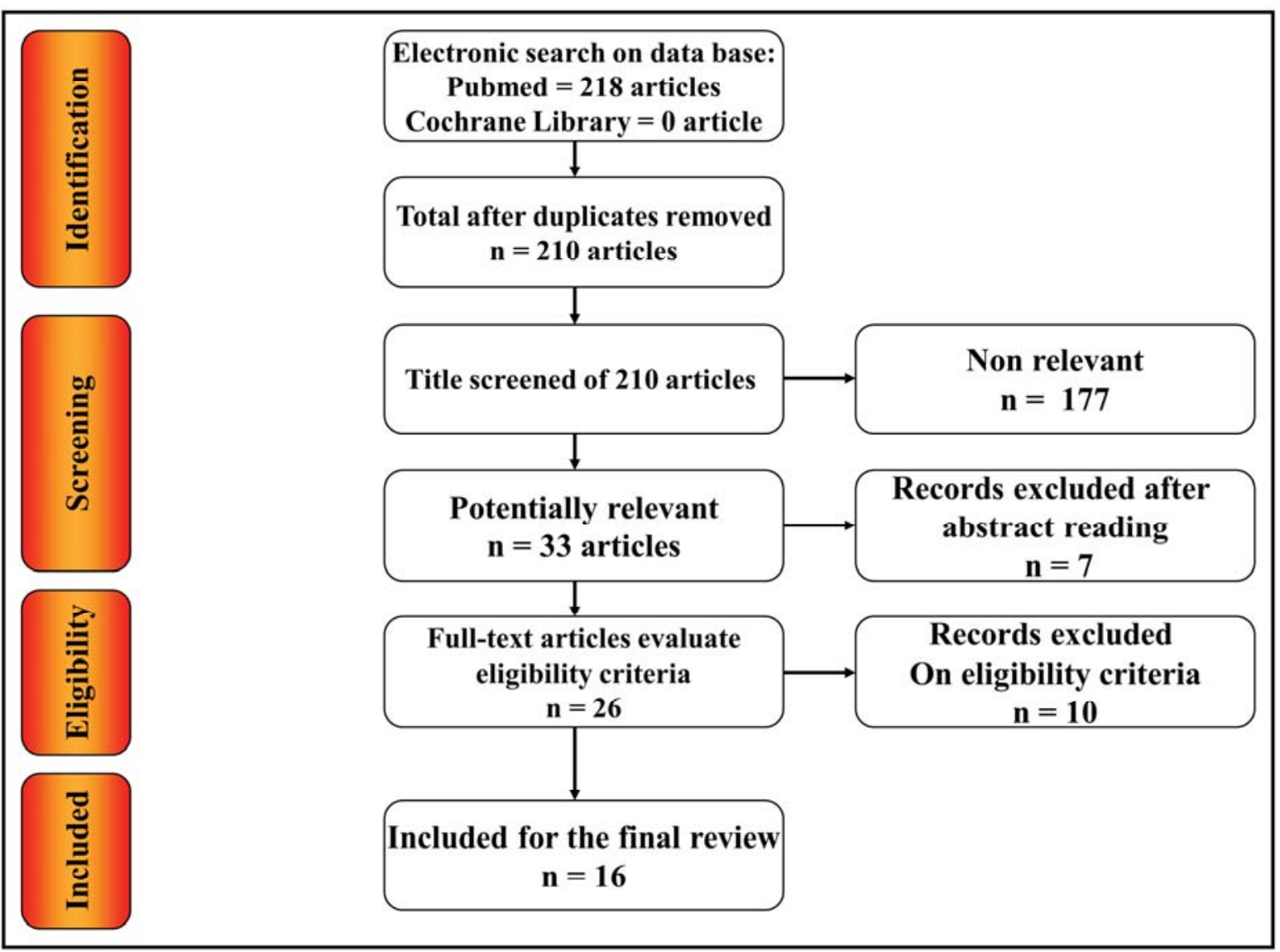




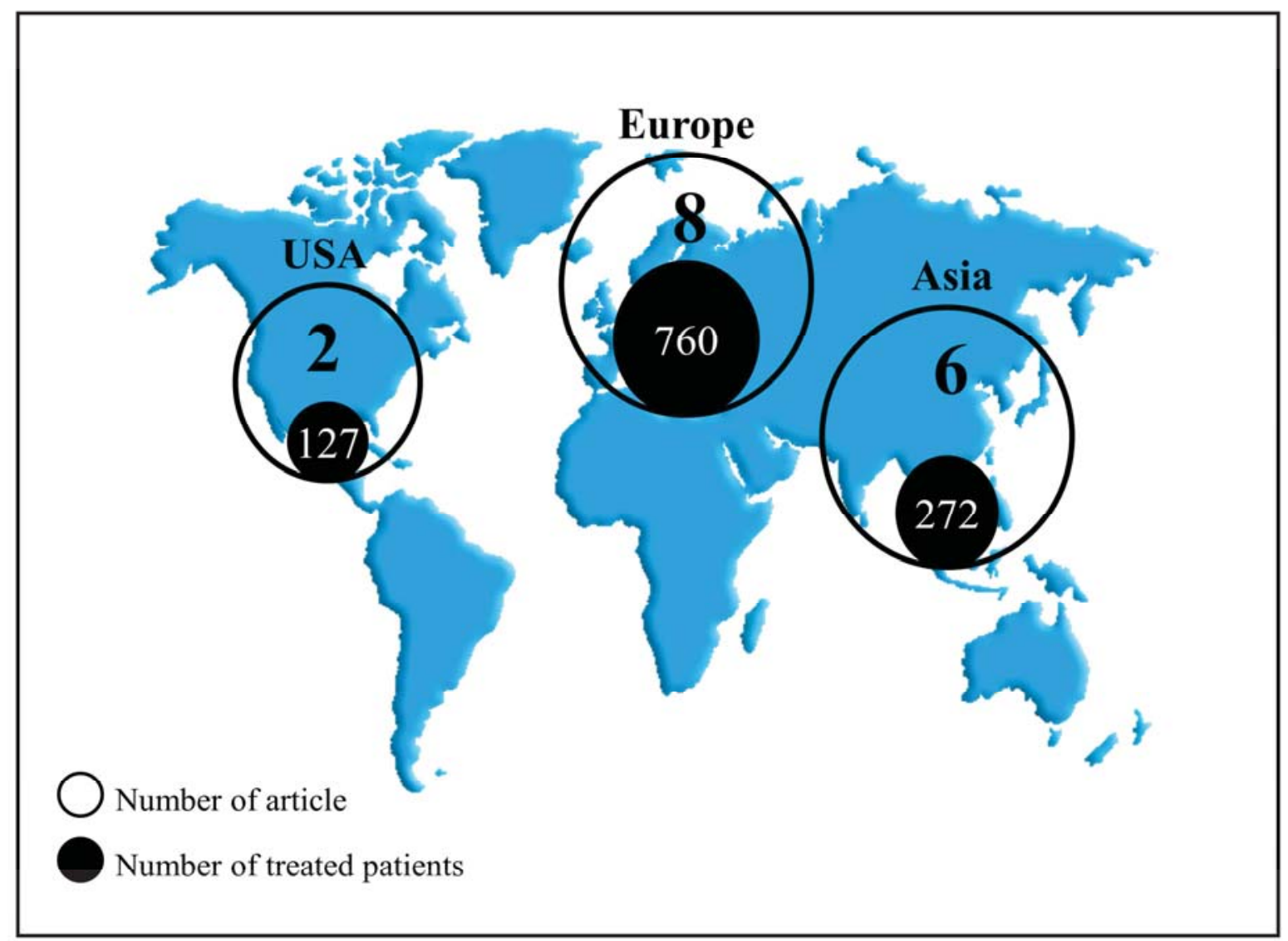




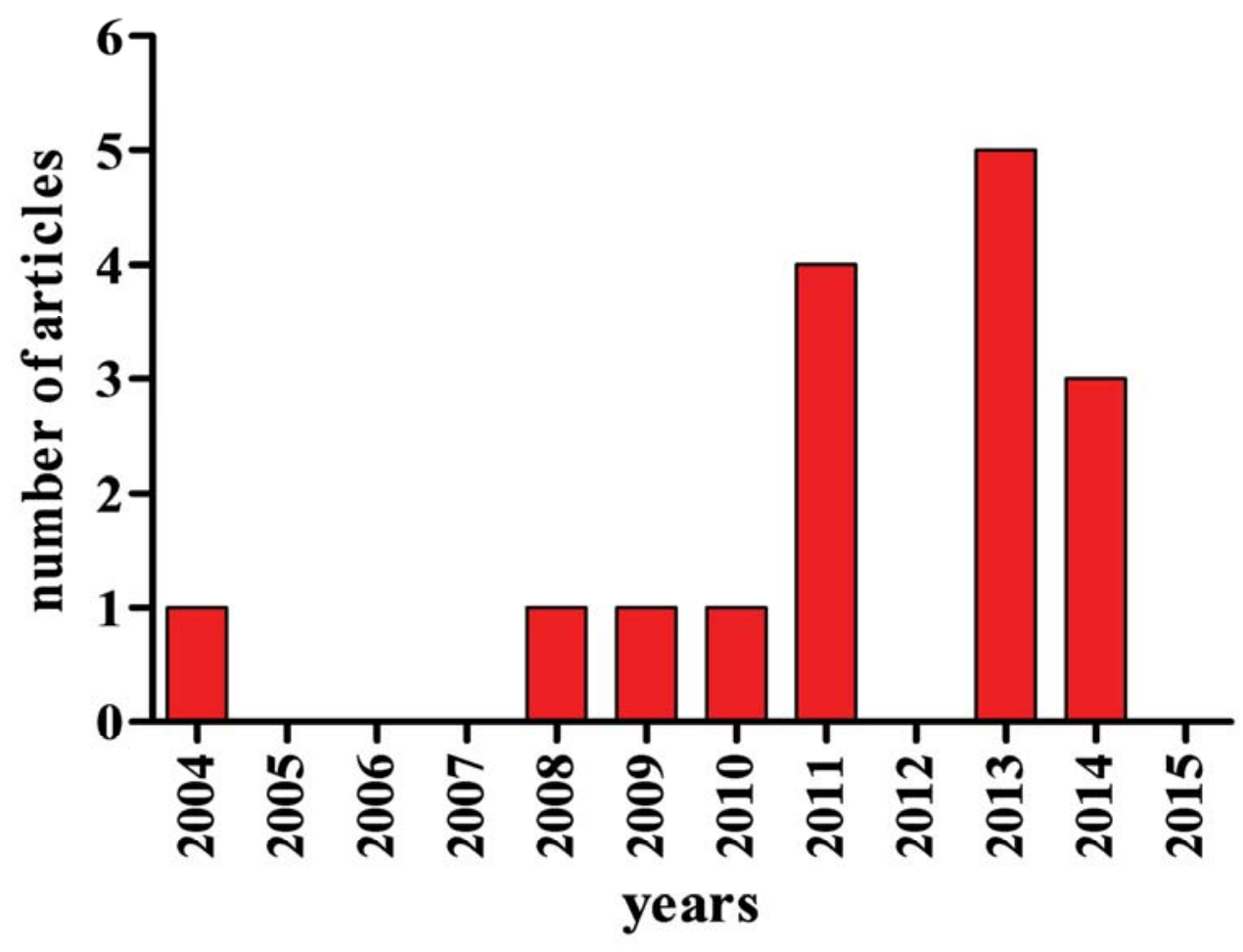

